\title{
Nebulized colistin for treatment of ventilator-associated pneumonia caused by multidrug-resistant Gram-negative bacteria: we still need to straighten out the dose!
}

\author{
Patrick M. Honore*, Rita Jacobs, Inne Hendrickx, Elisabeth De Waele, Jouke De Regt and Herbert D. Spapen
}

See related research by Zampieri et al., http://ccforum.com/content/19/1/150

We applaud the extensive systematic review and metaanalysis by Zampieri and colleagues on inhaled antibiotics for ventilator-associated pneumonia (VAP) [1] but would like to add some comments regarding inhaled colistin for treatment of VAP caused by multidrugresistant Gram-negative bacteria (MDR-GNB).

In patients with cystic fibrosis, the equivalent of 160 mg colistimethate sodium (CMS) produced high and therapeutic endobronchial concentrations [2]. However, to be effective in VAP caused by MDR-GNB, colistin must attain pulmonary concentrations that substantially exceed minimal plasma inhibitory levels for these microorganisms. Colistin aerosols used in the predominantly retrospective and observational studies summarized by Zampieri and colleagues contained CMS doses ranging from 80 to $300 \mathrm{mg}$ [1]. These doses may be insufficient to grant any significant or additional therapeutic value to inhaled colistin, especially when used together with intravenous antibiotics. Indeed, a total daily inhaled dose of $240 \mathrm{mg}$ CMS was found to be inadequate to treat lung infection caused by MDR-GNB [3]. A recent review recommended inhalation of $160 \mathrm{mg}$ CMS every $8 \mathrm{~h}$ for severe pulmonary infections [4]. Finally, a daily dose of $1,200 \mathrm{mg}$ inhaled CMS used in monotherapy or associated with a 3-day course of intravenous aminoglycosides cured VAP caused by MDR-GNB as effectively as VAP caused by $\beta$-lactam susceptible GNB [5]. In contrast with intravenous administration, high doses of nebulized colistin are not associated with an increased risk of kidney injury, even when given for a prolonged period of time [5].
We strongly salute aerosolized colistin as an important alternative or adjunct therapy to treat VAP caused by MDR-GNB, provided that the daily inhaled dose is sufficiently high.

\section{Abbreviations \\ CMS: Colistimethate sodium; MDR-GNB: Multidrug-resistant Gram-negative bacteria; VAP: Ventilator-associated pneumonia.}

\section{Competing interests}

The authors declare that they have no competing interests.

\section{Authors' contributions}

$\mathrm{PMH}$ and HDS designed the paper. PMH, RJ, IH, EDW, JDR, and HDS participated in drafting the manuscript.

Published online: 26 June 2015

\section{References}

1. Zampieri FG, Nassar Jr AP, Gusmao-Flores D, Taniguchi LU, Torres A, Ranzani OT. Nebulized antibiotics for ventilator-associated pneumonia: a systematic review and meta-analysis. Crit Care. 2015;19:150.

2. Ratjen F, Rietschel E, Kasel D, Schwiertz R, Starke K, Beier H, et al. Pharmacokinetics of inhaled colistin in patients with cystic fibrosis. J Antimicrob Chemother. 2006;57:306-11.

3. Athanassa ZE, Markantonis SL, Fousteri MZ, Myrianthefs PM, Boutzouka EG, Tsakris A, et al. Pharmacokinetics of inhaled colistimethate sodium (CMS) in mechanically ventilated critically ill patients. Intensive Care Med. 2012;38:1779-86.

4. Gurjar M. Colistin for lung infection: an update. J Intensive Care. 2015;3:3.

5. Lu Q, Luo R, Bodin L, Yang J, Zahr N, Aubry A, et al. Efficacy of high-dose nebulized colistin in ventilator-associated pneumonia caused by multidrugresistant Pseudomonas aeruginosa and Acinetobacter baumannii. Anesthesiology. 2012;117:1335-47.

\footnotetext{
* Correspondence: Patrick.Honore@uzbrussel.be

ICU Department, Universitair Ziekenhuis Brussel, Vrije Universiteit Brussel, 101 Laarbeeklaan, 1090 Jette, Brussels, Belgium
} 